\title{
Evaluation of Rock Fall Hazards Using Lidar Technology
}

\author{
Norbert Maerz ${ }^{1}$, Travis Kassebaum ${ }^{2}$, Ken Boyko ${ }^{1}$ and James Otoo ${ }^{3}$ \\ 1. Geological Engineering, Missouri University of Science and Technology, Missouri 6540, USA \\ 2. Terracon Consulting Engineers and Scientist, Missouri 63055, USA \\ 3. Chevron North America Exploration and Production, Texas 77002, USA
}

\begin{abstract}
Lidar (light detection and ranging) is a relatively new technology that is being used in many aspects of geology and engineering, including researching the potential for rock falls on highway rock cuts. At Missouri University of Science and Technology, we are developing methods for measuring joint orientations remotely and quantifying the raveling process. Measuring joint orientations remotely along highways is safer, more accurate and can result in larger and more accurate data sets, including measurements from otherwise inaccessible areas. Measuring the nature of rock raveling will provide the data needed to begin the process of modeling the rock raveling process. In both cases, terrestrial lidar scanning is used to generate large point clouds of coordinate triplets representing the surface of the rock cut. Automated algorithms have been developed to organize the lidar data, register successive images without survey control, and removal of vegetation and non-rock artifacts. In the first case, we look for planar elements, identify the plane and calculate the orientations. In the second case, we take a series of scans over time and use sophisticated change detection algorithms to calculate the numbers and volumes of rock that has fallen off the rock face.
\end{abstract}

Key words: Lidar, rock fall, hazard, rock cuts, highway.

\section{Introduction}

\subsection{Rock Falls}

Rock falls are a major geological hazard in many states with mountainous or hilly terrain. The safety and convenience of the motoring public demands that highway rock cuts be made as safe as possible, while expenditures on remediation are always limited by often shrinking budgets. Catastrophic failures of rock cuts can result in property damage, injury and even death. Highways impeded by even small spills of rock material are an inconvenience for motorists. Rock fall hazard assessment in the USA has traditionally been a reactive process.

Highways that traverse through rocky terrains often require that artificial vertical slopes are cut by blasting techniques to facilitate the highway construction. A constant danger to the motoring public is large blocks of rock to fall or slide down, at worst killing and

Corresponding author: Norbert Maerz, Ph.D., program head, research fields: rock mechanics, engineering, characterization and lidar scanning. E-mail: Norbert@mst.edu. injuring members of the motoring public, and at best blocking the highway and impeding traffic flow.

\subsection{Discontinuity Controlled Rock Falls (Conducive to Quantitative Analysis)}

Many of these failures result because of release along planar cracks or discontinuities in rock mass. Whether or not failure occurs will depend on the orientation of the cracks, individually or in combinations (Fig. 1). The cracks or discontinuities tend to cluster in terms of their orientations into typically three or more sets, which tend to be mutually orthogonal, or roughly at $90^{\circ}$ to each other (Fig. 2). Knowing the orientations of the discontinuities, it can lead to stability prediction based on well-established analytical tools [1].

Fig. 3 shows the time honored stereonet projection method [2] where each data point, consisting of a normal vector to an individual discontinuity plane, is assigned to a discontinuity set by using cluster analysis. Cluster analysis techniques are described in Refs. [3-7]. 

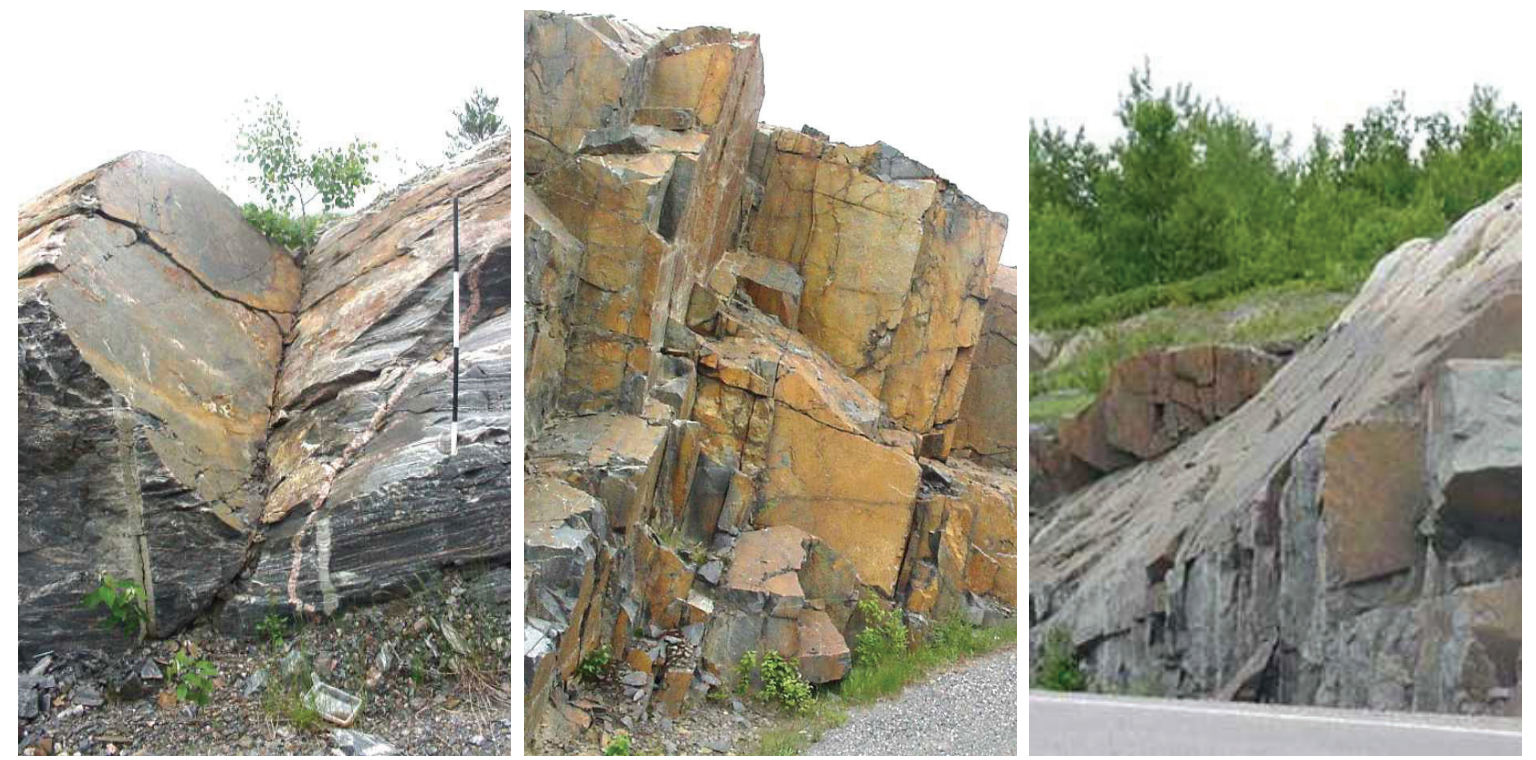

Fig. 1 Example of (a) wedge; (b) toppling; (c) planar failures along road cuts.

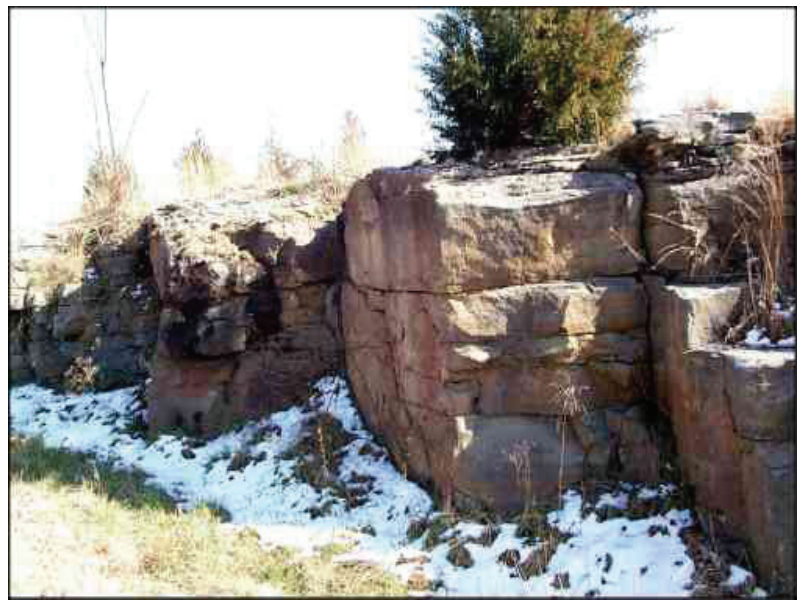

Fig. 2 Orthogonal nature of joint sets. Measurements of the "cracks" or discontinuities are displayed in Fig. 3.

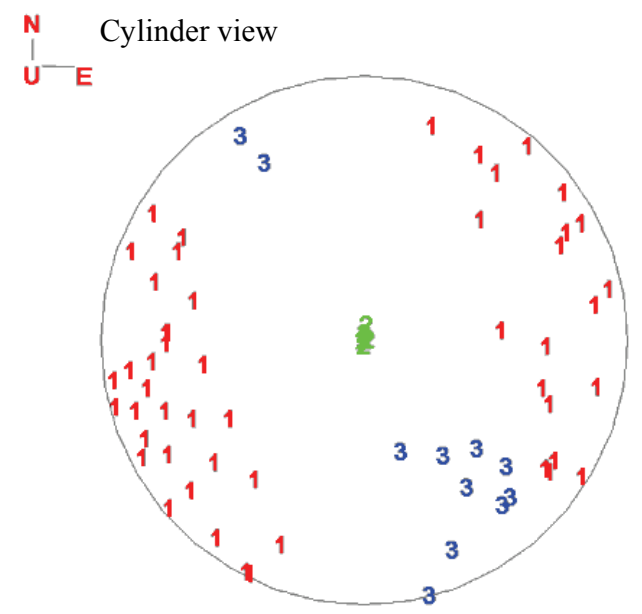

Fig. 3 Projections of vectors normal to discontinuity plane on a unit lower hemisphere, clustered into three sets.
The orientations can be and have been traditionally measured using manual compass and clinometer methods. These methods are however slow, tedious, cumbersome and dangerous in some cases because of potential falling rock, and are often limited to easily accessible locations like the base of the slope.

Once discontinuities on a rock face are identified, traditional graphical or computational techniques can be used to determine the kinematic feasibility of failure (Fig. 4). Standard modeling techniques such as limiting equilibrium analysis can then be used to determine if failure will indeed take place (Fig. 5) [1, 8-16].

These deterministic models can then be used to predict the stability of the rock cuts based on the interaction of the discontinuities.

\subsection{Raveling Type Rock Falls (Not Conducive to Quantitative Analysis)}

In many terrains, the discontinuities are not oriented in such a way that they contribute to create wedge, planar sliding or toppling failures or other easily analyzed failure mechanisms (Fig. 6). Franklin and Senior [17, 18] report that of 415 analyzed cases of failure in Northern Ontario, only 33\% of failures involved these mechanisms (23\% toppling, $8 \%$ planar sliding, $2 \%$ wedge sliding). 


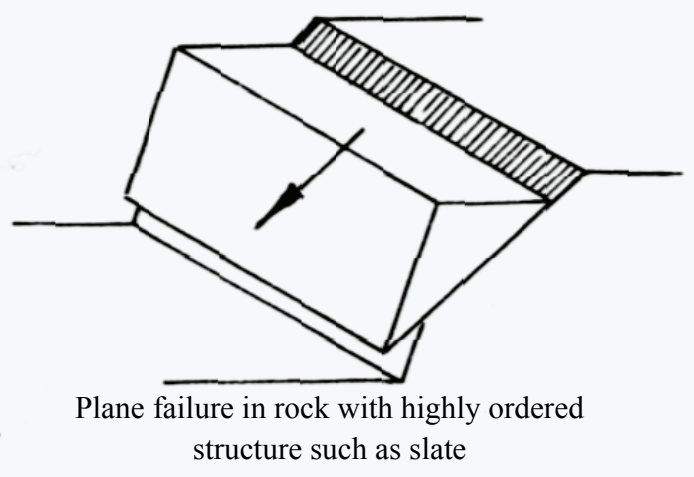

(a)

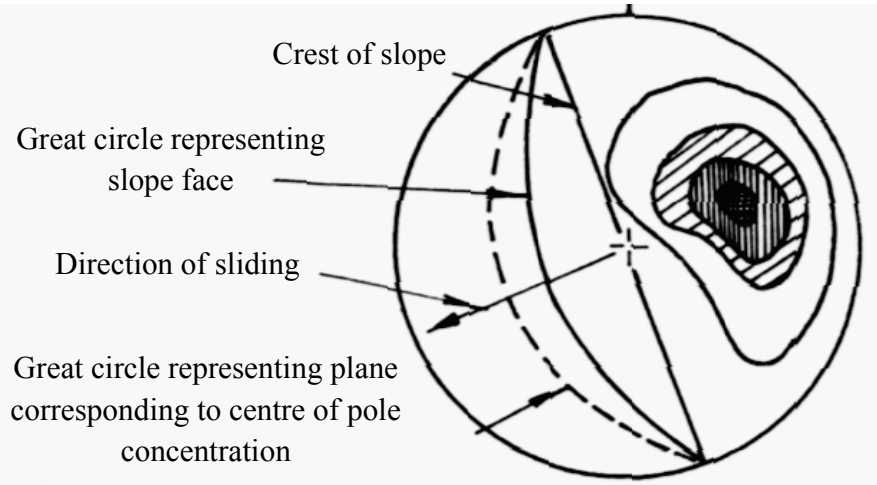

(b)

Fig. 4 (a) Planar failure geometry; (b) graphical method of determining if slide failure is kinematically possible after Hoek and Bray [1].

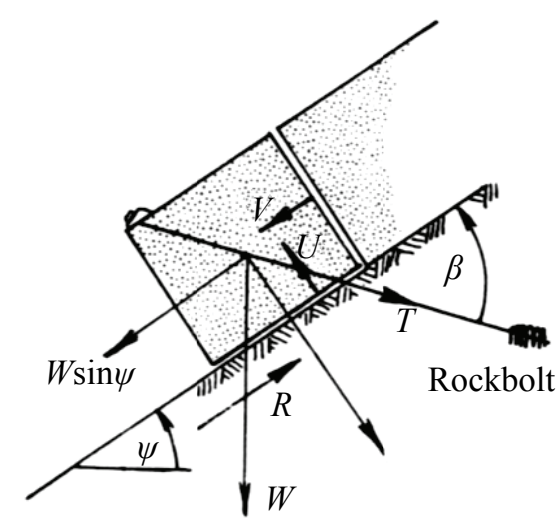

(a)



(b)

Fig. 5 (a) Limiting equilibrium analysis applied to planar features; (b) wedge features after Hoek and Bray [1].

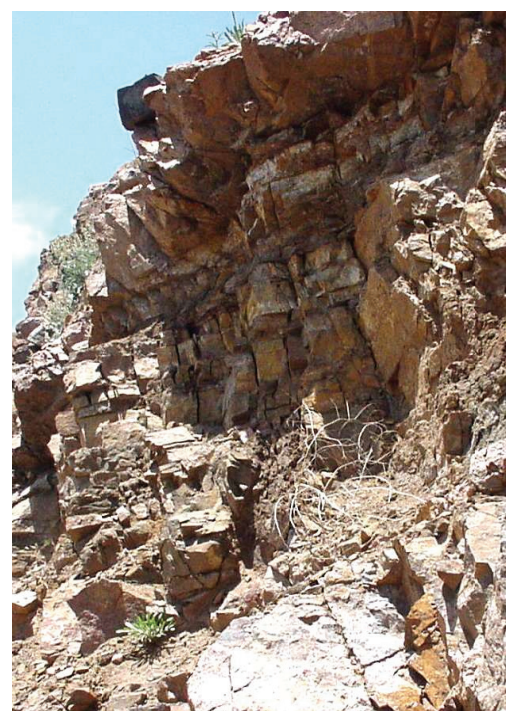

(a)

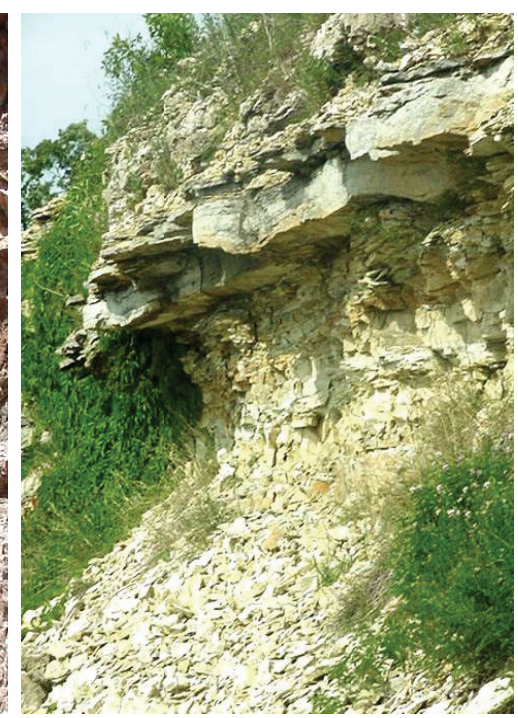

(b)

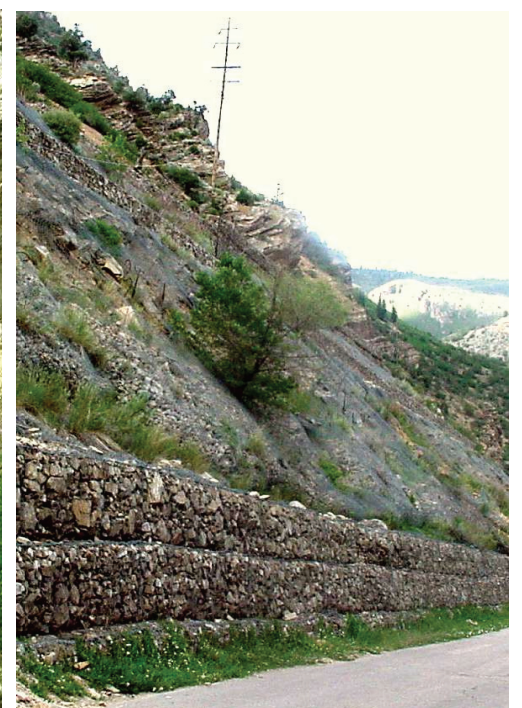

(c)

Fig. 6 Example of: (a) raveling; (b) undercutting; (c) rolling failures along road cuts.

In the Northern Ontario study, $65 \%$ of the failures were the "raveling" type. These included raveling
(25\%), overhang/undercutting failure $(15 \%)$, ice jacking (14\%) and rolling blocks (11\%). In other 
terrains, most notably flat lying sedimentary rock, such as those found in most parts of the US, the predominant failure mechanism being of the raveling type is even greater.

Raveling failure, the most common type of rock failure, is poorly understood. Analysis is mostly descriptive and prediction of the amount of raveling is typically an empirical exercise in guessing based on extrapolation of visual evidence. Raveling failures are usually slow and time dependent, but can also be catastrophic if they involve large blocks falling or many blocks releasing at once. Large blocks are often results of the collapse of overhanging ledges that have been undercut by raveling.

The literature abounds with mention of raveling $[1,8,19,20]$. Rock hazard rating systems use raveling as a parameter to determine the durability of rock cuts [21-23]. European research has investigated the processes and morphology of raveling, although in a qualitatively observational way [24-26]. In short, there is no quantitative mechanism and model available to describe the raveling process, and consequently, no predictive tools. Mitigation efforts make use of empirical observation and engineering judgment.

\section{Terrestrial Lidar Technology}

As a distance measuring device, lidar (light detection and ranging) replaces traditional methods of laser surveying, which take individual measurements and require reflective targets to measure distances and angles. Lidar is more analogous to radar, in which the scanning laser can make thousands of point measurements per second, reflecting off any surface and returning a point cloud, which can be used by sophisticated software to create a very detailed 3D surface map. The scanner uses either time of flight or phase shift sensors technology. The result is a million of points reflected from the surface. The points are represented by $x y z$ coordinates, these $x y z$ coordinates and their associated intensity values are known as a "point cloud". At Missouri S\&T, we have two lidar scanners (Fig. 7). The Leica ScanStation II is a time of flight scanner capable of scanning up to $300 \mathrm{~m}$ at a maximum rate of 50,000 points per second. The Leica HDS6000 is a phase shift scanner capable of scanning up to $100 \mathrm{~m}$ at a maximum rate of 500,000 points per second. Both scanners have an accuracy of a bit less than $1 \mathrm{~cm}$ for a single measurement, but accuracy can be improved up to an order of magnitude for modeled surfaces, and even greater for special circumstances. The ScanStation II in addition has a built-in camera, so it is capable of adding optical color information to the point cloud.

Kemeny et al. [27] characterized rock masses using lidar and automated point cloud processing, and also analyzed rock slope stability using lidar and digital images, including measuring and clustering discontinuity orientations. Lidar was used by Mikos et

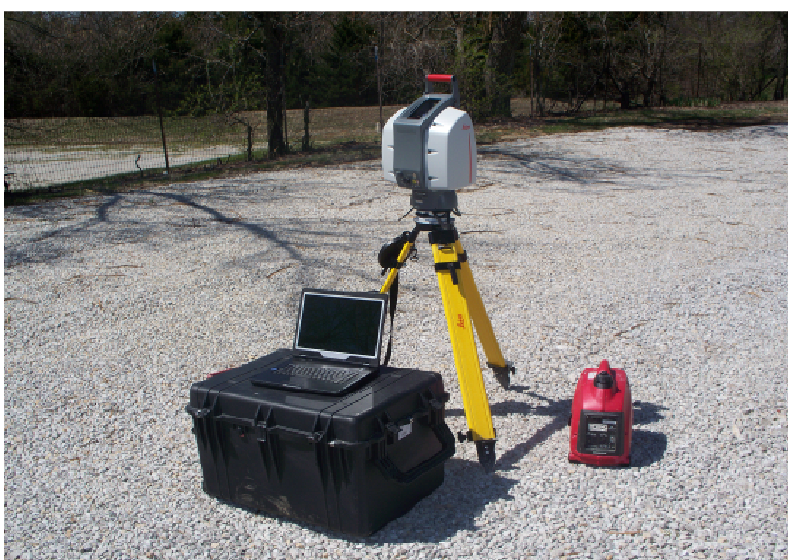

(a)

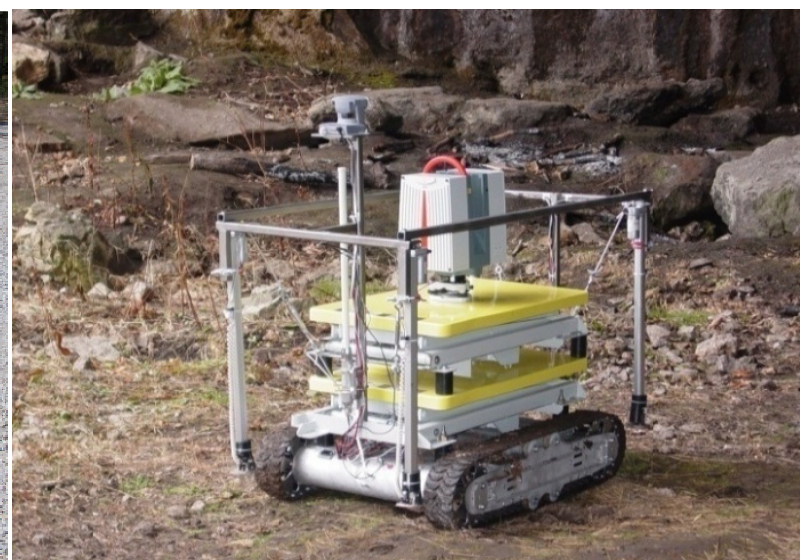

(b)

Fig. 7 (a) Leica ScanStation II time of flight scanner with integrated optical camera; (b) Leica HDS 6000 phase shift scanner on remote controlled robotic buggy. 
al. [28] to study rock slope stability. Lim et al. [29] used photogrammetry and laser scanning to monitor processes active in hard rock coastal cliffs. High resolution lidar data was used by Sagy et al. [30] to quantitatively study fault surface geometry. Enge et al. [31] illustrated the use of lidar to study petroleum reservoir analogues.

\section{Lidar Discontinuity Orientation Measurements}

To measure joint orientations, lidar scans are taken of the joints to be measured. To simplify and speed up the process, no survey control is needed. It is simply required to measure the strike of a single sub-vertical feature in the scan. In addition, since only a single lidar scan is sufficient, no image registration is required. It must be noted that in the case of the Leica ScanStation II, the optical image is automatically registered to the scanned point cloud. Two types of rock faces/cuts are possible (Fig. 8). In the first case, some rock faces are composed almost exclusively of natural discontinuity surfaces. The orientation of each of these surfaces can be and should be measured. These are conducive to automatic or semi-automated analysis as described in Refs. [32-39]. Fig. 9 shows an example of an automated analysis of such a rock face, in which the discontinuity measurements are clustered into sets and each resulting set is represented by a different color.

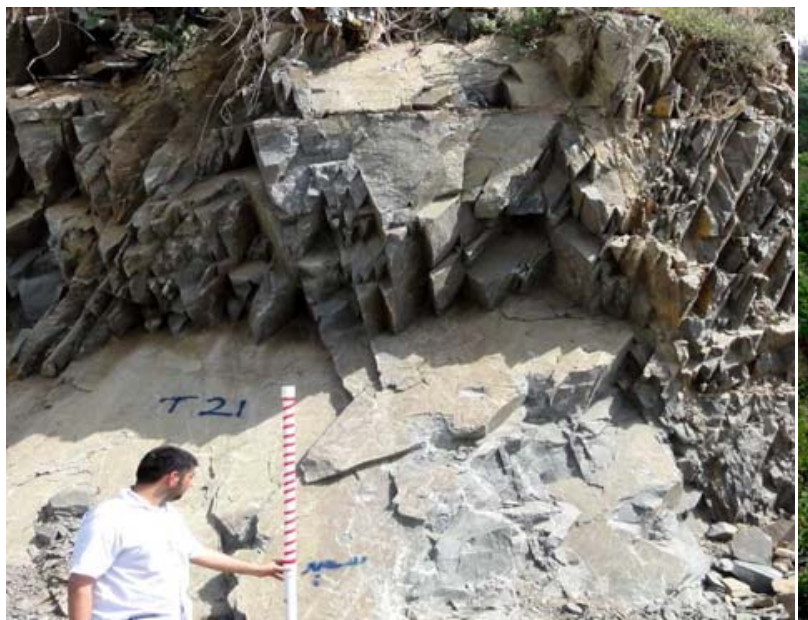

(a)

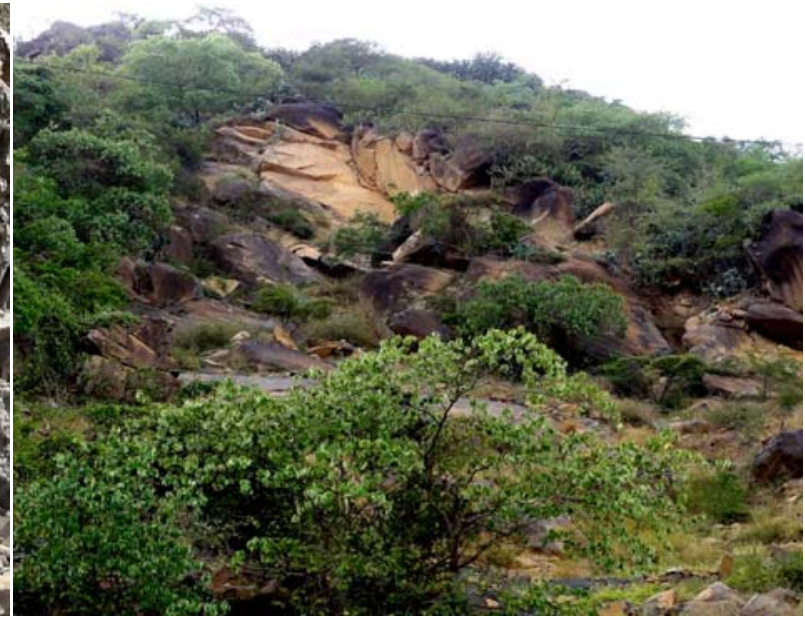

(b)

Fig. 8 (a) Rock faces with $100 \%$ coverage of natural joint surfaces; (b) rock faces with significant ambiguity as to the location of natural joint surfaces.

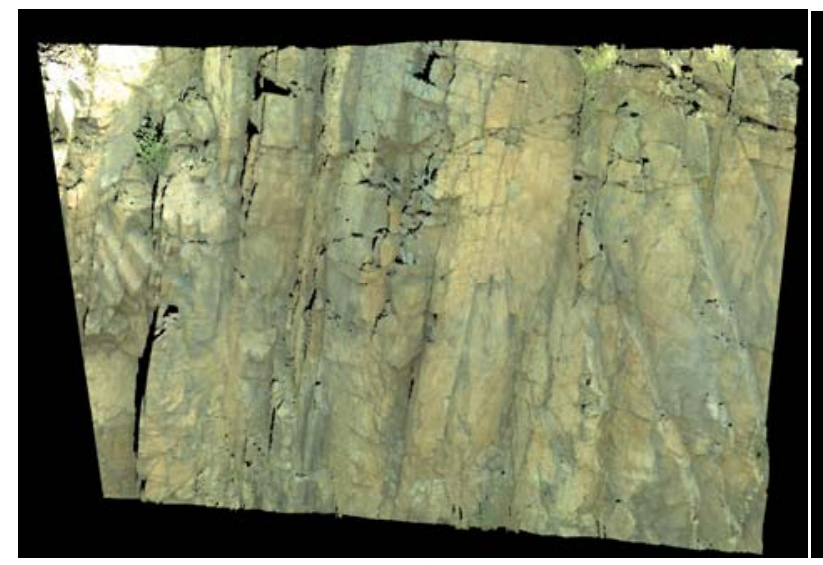

(a)



(b)

Fig. 9 (a) Point cloud of a Missouri rock cut in ignimbrite rock; (b) identification of discontinuity orientations. Each different color represents discontinuities of similar orientations. 
On the other hand for rock cuts that have sparse representation of natural joint surfaces, it is often the easiest just to manually identify individual discontinuities on a lidar image viewer and pick (on the planar discontinuity surface) three co-planar, non co-linear points. Fig. 10 shows an example of using a point cloud viewer to select three points on a discontinuity surface. The discontinuity orientation can be determined by the classic three-point solution [40].

Figs. 11 and 12 show the results of a small verification study where lidar measurements are compared with manual measurements using a Brunton compass.

\section{Raveling Measurements}

To quantify raveling of rock, scans of a raveling rock face are taken over a period of time. Again, to simplify and speed up the process, no survey control is needed, it is simply required to position the lidar unit in the approximately same place and scan approximately the same area. Algorithms for automated registration are used to superimpose the two scanned sets and then the volume differences between the two sets are measured and displayed. Fig. 13 shows an example of a raveling

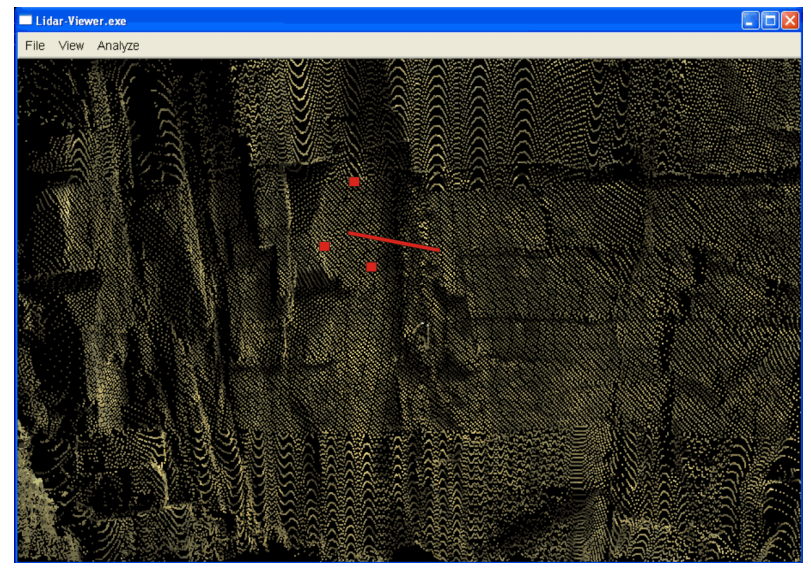

Fig. 10 Picking three points on a discontinuity surface to calculate orientation.

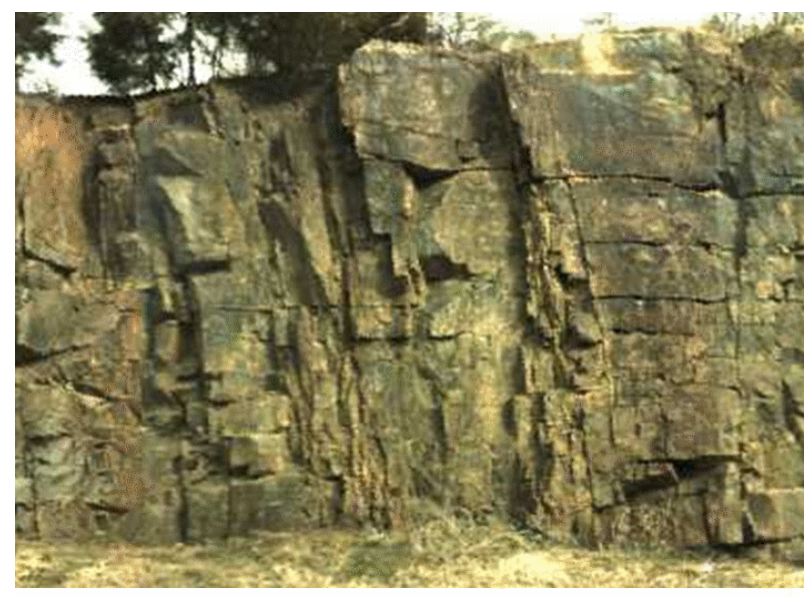

Fig. 11 Rock cut selected for verification study.

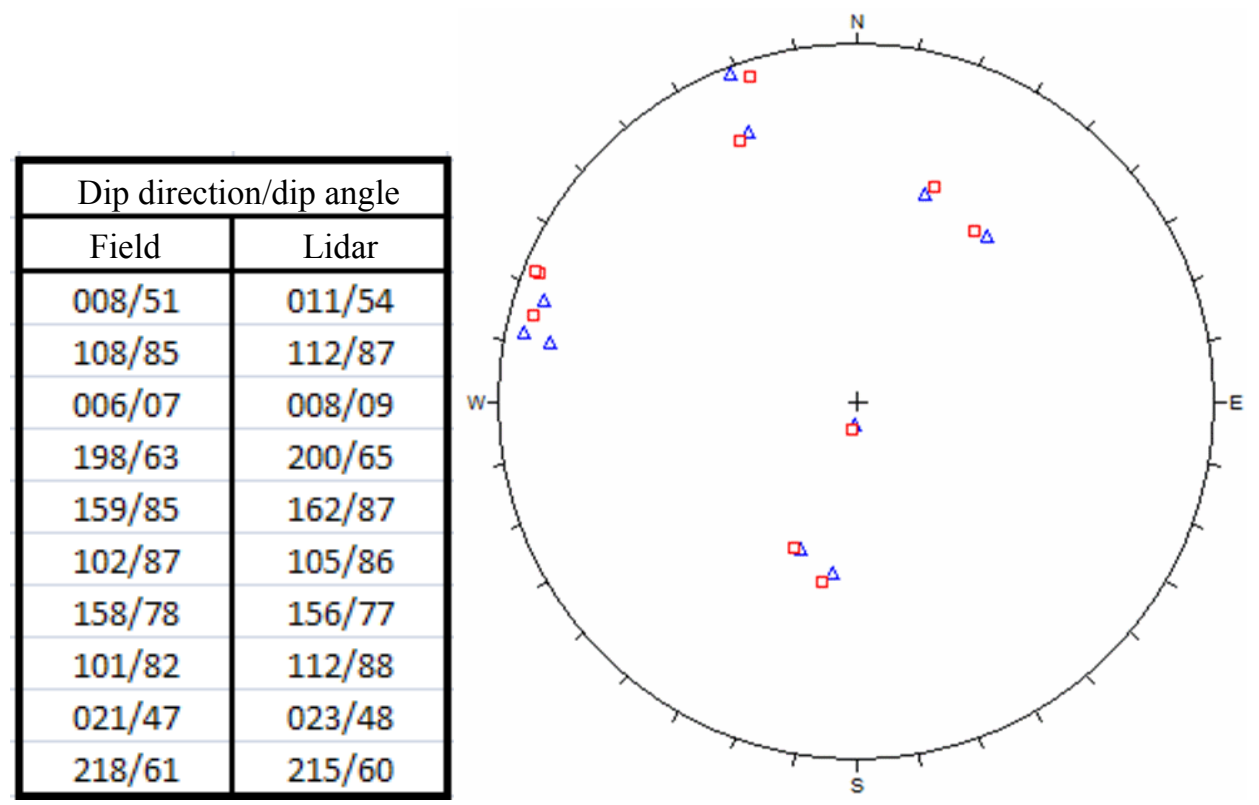

Fig. 12 Results of verification study comparing manual measurements with lidar measurements. On the lower hemisphere projection, red points are lidar measurements, blue points are manual measurements. 




Fig. 13 Scan section of a rock face near a local quarry.

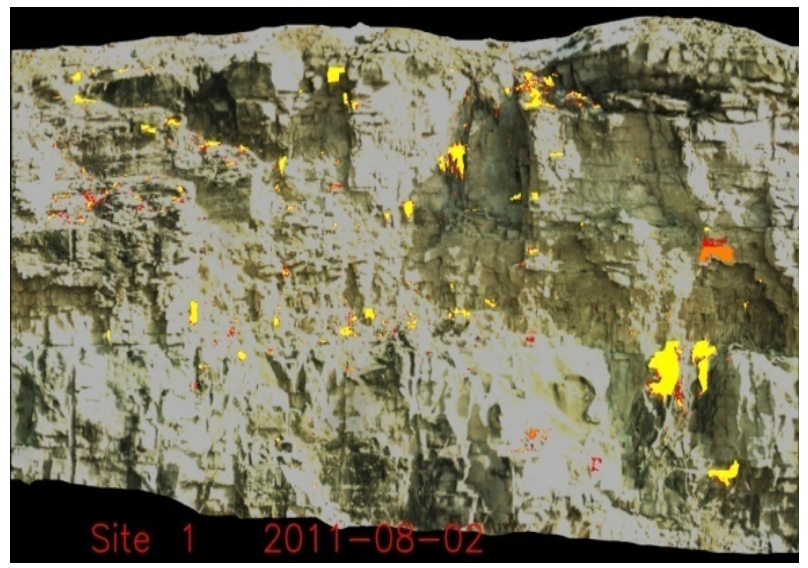

Fig. 14 Point cloud of the scan and measured progressive raveling loss (yellow, July 15, orange, July 26, and red, August 2).
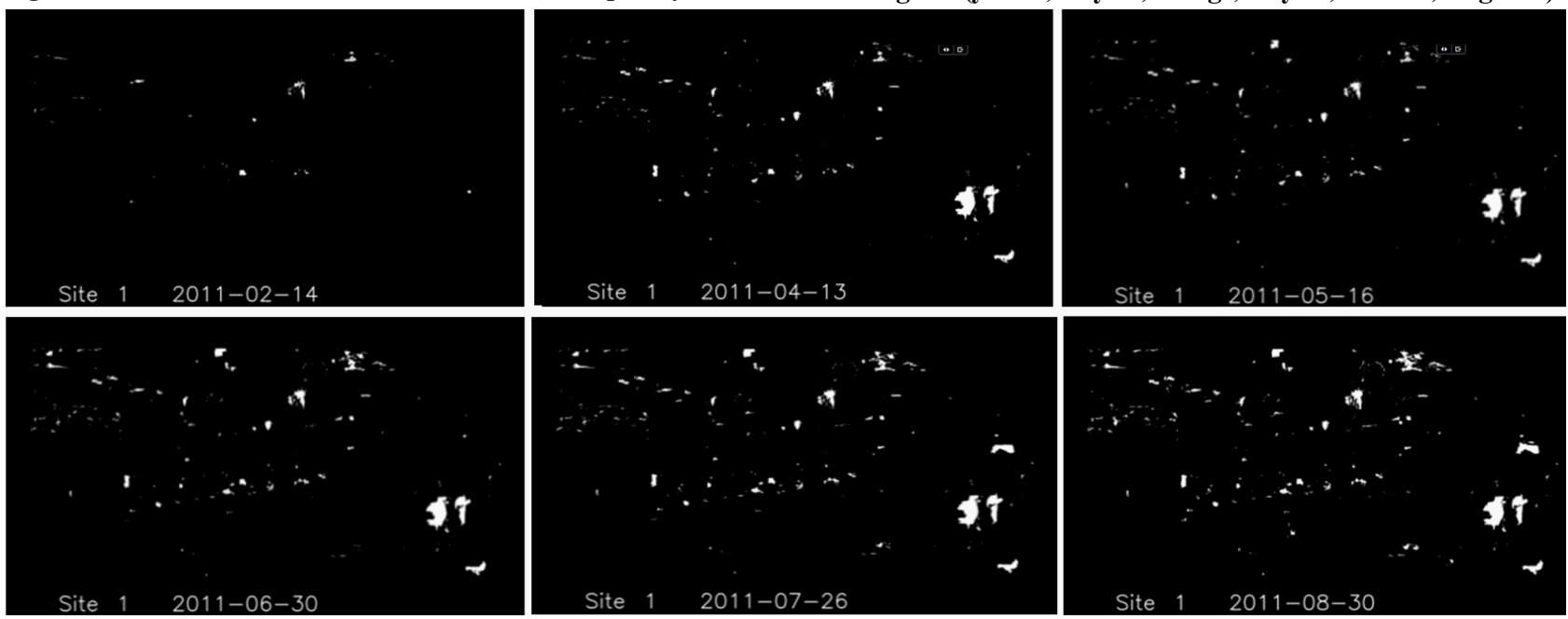

Fig. 15 Part of the sequence of 16 images showing the increase in missing (fallen) blocks as a function of time.

rock cut in weathered dolomite. Fig. 14 shows the results of three sequential measurements with the missing pieces highlighted for a 6 month pilot study.

To demonstrate the feasibility of the proposed technique, a small, 6 months' study was undertaken (Fig. 15). Two small and local rock cuts (one in and one near a local quarry) were imaged using lidar, 18 separate times over that period. At the same time, measurements of rainfall and ground vibration from blasting were taken. Resolution was found to be $3 \mathrm{~mm}$ for Site 1 and $8 \mathrm{~mm}$ for Site 2, with an average of 6.7 million data points per scan. The smallest rock face that could be detected is $9 \mathrm{~mm}$ wide. Software was developed to register the point clouds (with an average root mean square error of $2.5 \mathrm{~mm}$ ) scanned at different times and measure the volume of the fallen rock. All softwares are developed in $\mathrm{C}++$, compiled using the GNU G++ complier, and run on Ubuntu ${ }^{\circledR}$ Linux. The processing sequence was as follows:

(1) pre-loading determines the minimum and maximum ranges of the horizontal and vertical components of the observation set;

(2) load individual triplets $(x, y, z)$, sorted according to position;

(3) filling gaps by interpolating between triplets;

(4) register the image to know coordinate system using automatic algorithms;

(5) determine maximum common crop boundary for all temporal data sets;

(6) crop the image so that each image consistently covers the same area; 
(7) removal of vegetation and all non-rock artifacts. These features represent themselves as sharp spikes in the lidar surface. A specialized spatial filter was developed to detect these high-spatial frequency features and eliminate them from the lidar surface. The new method employs a virtual articulating conical probe to scan the "backside" of the lidar surface. If the probe tip can reach the surface without intersection, the tip is judged to be on rock. If the probe tip cannot reach the surface without intersection, the tip is judged to be in contact with "thin" vegetation;

(8) creation of a difference surface between any two scans;

(9) segmentation of individual (missing) rocks. The raw "difference surface" contains both real data (representations of individual lost rocks) and false data artifacts: residual vegetation not completely removed parallax errors caused by residual errors in the registration process; and hidden/occluded surfaces generated from imprecise recovery of the lidar scanner set-up position between successive scans;

(10) volume calculation.

Preliminary correlations (Fig. 16) between volume of blocks lost and freeze-thaw cycles, blasting episodes and rainfall are somewhat tentative at this point. Site 2 seems significantly affected freeze-thaw cycles in correlating Scan \#2. In the area of Scans \#11-13, as the rainfall decreases to near zero, the volume of blocks lost also trends to zero. The difference between Scan \#2 of the two sites remains unanswered.

There is also an indication that rainfall events may have a greater effect on rock fall in the winter when combined with the freeze-thaw activity. Even though the rock cuts were near an active quarry (one inside the quarry and one just outside), there seems to have been no effect from blasting episodes on rock fall.

The results show that, in some incremental scans, there were some small volume gains. Observations suggest that this is real and it is a result of small quantities of rock accumulating on ledges after having fallen from higher up. More work on the algorithms may increase the fidelity of the lost volume measurement.

Ultimately, the goal of this work is to provide verification for numerical models that will be used to model the raveling process.

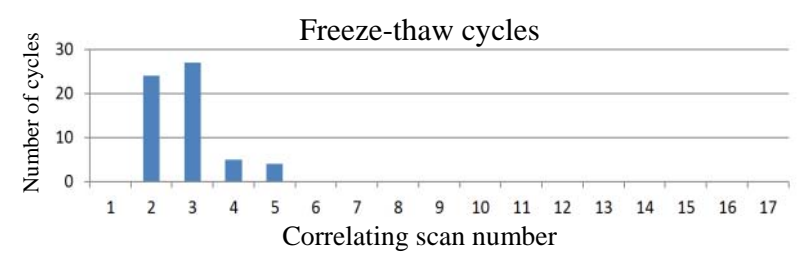

(a)

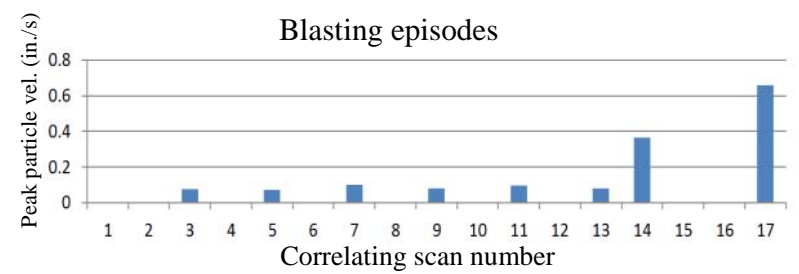

(b)

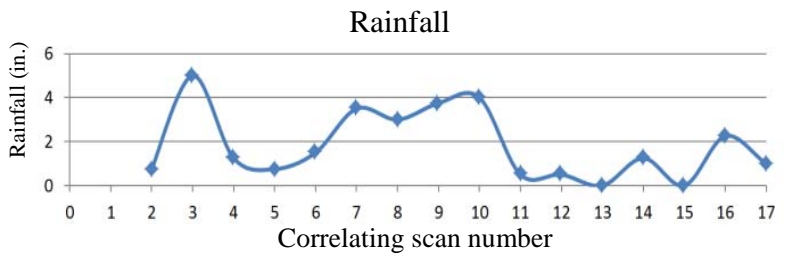

(c)

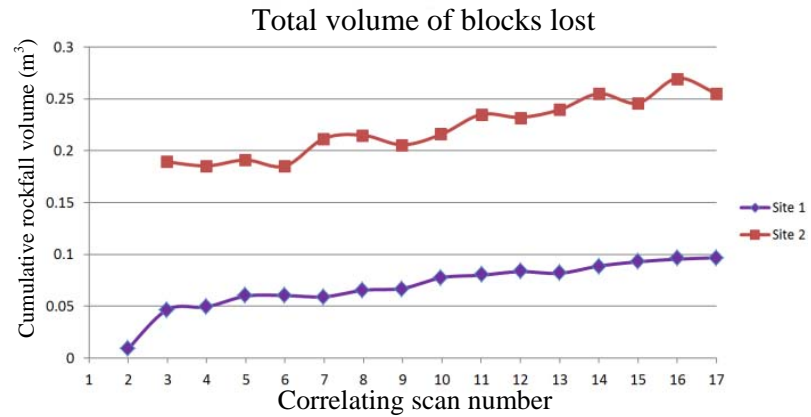

(d)

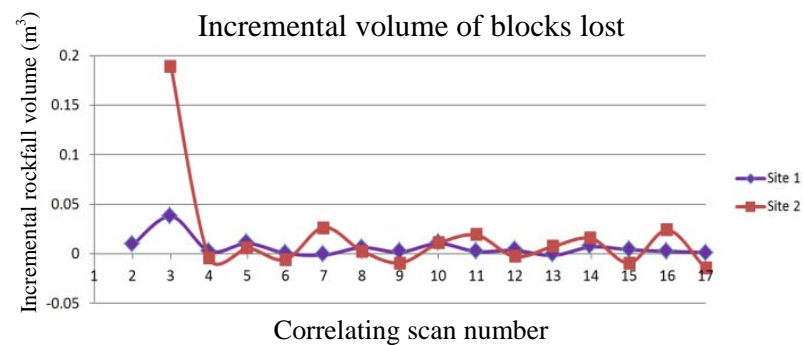

(e)

Fig. 16 Results of the study: (a) freeze-thaw cycles; (b) blasting episodes and intensity; (c) rainfall; (d) total volume of blocks lost; (e) incremental volume of blocks lost. 


\section{Conclusions}

Lidar technology provides tremendous new opportunities for measurement and characterization of rock cuts. Measurements using lidar are superior to manual measurements and older technologies in which they produce vast amounts of data, quickly, safely and with less sampling bias. What required are algorithms, both simple and sophisticated, which use the lidar data to characterize the rock cuts and provide input to predictive tools.

In the case of structurally controlled rock falls, the lidar measurements are now well known and have proven to be accurate and useful as inputs to stability modelling programs.

In the case of the raveling type rock falls, the lidar measurements are still being developed and improved, and will ultimately be used in developing rock fall modelling algorithms.

\section{Acknowledgments}

The authors would like to thank the University of Missouri Research Board and the Missouri S\&T Center for Infrastructure Engineering for helping to fund this project.

\section{References}

[1] Hoek, E., and Bray, J. 1981. Rock Slope Engineering. London: The Institution of Mining and Metallurgy.

[2] Priest, S. D. 1985. Hemispherical Projection Methods in Rock Mechanics. London: George Allen \& Unwin.

[3] Maerz, N. H., and Zhou, W. 1999. "Multivariate Analysis of Bore Hole Discontinuity Data.” In Proceedings of the 37th US Rock Mechanics Symposium, 431-8.

[4] Maerz, N. H., and Zhou, W. 2000. "Discontinuity Data Analysis from Oriented Boreholes, Pacific Rocks.” In Proceedings of the Fourth North American Rock Mechanics Symposium, 667-74.

[5] Zhou, W., and Maerz, N. H. 2001. "Multivariate Clustering Analysis of Discontinuity Data: Implementation and Applications.” In Proceedings of the 38th US Rock Mechanics Symposium, 861-8.

[6] Zhou, W., and Maerz, N. H. 2002. "Implementation of Multivariate Clustering Methods for Characterizing Discontinuites from Oriented Boreholes." Computers \& Geosciences 28 (7): 827-39.
[7] Maerz, N. H., and Zhou, W. 2005. "Multivariate Clustering Analysis of the ECRB (Enhanced Characterization of the Repository) Cross Drift Discontinuities, Yucca Mountain Project, Alaska Rocks.” In Proceedings of the 40th US Rock Mechanics Symposium, 10.

[8] Piteau, D. R. 1979. Engineering Geology Considerations and Basic Approach to Rock Slope Stability Analysis for Highways, Part A, Rock Slope Engineering Reference Manual: FHWA Report-FHWA-TS-79-208. Federal Highway Administration.

[9] Piteau, D. R. 1979. Methods of Obtaining Geological, Structural, Strength and Related Engineering Geology Data, Part B, Rock Slope Engineering Reference Manual: FHWA Report-FHWA-TS-79-208. Federal Highway Administration.

[10] Piteau, D. R. 1979. Approach and Techniques in Geological Structural Analysis, Part C, Rock Slope Engineering Reference Manual: FHWA Report-FHWA-TS-79-208. Federal Highway Administration.

[11] Piteau, D. R. 1979. Slope Stability Analysis Methods, Part D, Rock Slope Engineering Reference Manual: FHWA Report-FHWA-TS-79-208. Federal Highway Administration.

[12] Piteau, D. R. 1979. Rock Slope Stabilization, Protection and Warning-Instrumentation Measures and Related Construction Considerations, Part E, Rock Slope Engineering Reference Manual: FHWA Report-FHWA-TS-79-208. Federal Highway Administration.

[13] Piteau, D. R. 1979. Blasting for Rock Slopes and Related Excavation Considerations, Part F, Rock slope Engineering Reference Manual: FHWA Report—FHWA-TS-79-208. Federal Highway Administration.

[14] Piteau, D. R. 1979. Description of Detail Line Engineering Geology Mapping Method, Part G, Rock Slope Engineering Reference Manual: FHWA Report_FHWA-TS-79-208. Federal Highway Administration.

[15] Brawner, C. O. 1994. Rockfall Hazard Mitigation Methods, Participant Workbook: FHWA Report-FHWA-SA-93-085. Federal Highway Administration.

[16] Konya, C. J., and Walter, E. J. 1991. Rock Blasting and Overbreak Control, FHWA Report-FHWA-HI-92-001. Federal Highway Administration.

[17] Franklin, J. A., and Senior, S. A. 1987. "Outline of RHRON, the Ontario Rockfall Hazard Rating System.” In Proceedings of International Symposium on Engineering Geology and The Environment, 647-56. 
[18] Franklin, J. A., and Senior, S. A., 1987. "Rockfall Hazards-Strategies for Detection, Assessment, and Remediation.” In Proceedings of International Symposium on Engineering Geology and The Environment, 657-63.

[19] Walkinshaw, J., and Santi, P. 1996. Shales and Other Degrable Materials, Landslides Investigation and Mitigation. TRB special report 247, Transportation Research Board.

[20] Kliche, C. 1999. Rock Slope Stability. Colorado: Society for Mining, Metallurgy and Exploration.

[21] Pierson, L. A., and van Vickle, R. 1993. Rockfall Hazard Rating System-Participants' Manual: FHWA Report_FHWA-SA-93-057. Federal Highway Administration.

[22] Senior, S. 1999. "Rockfall Hazard Remediation along Ontario Highways." In Proceedings of 50th Highway Geology Symposium, 276-86.

[23] Maerz, N. H., Youssef, A., and Lauer, R. 2004. "MORFH RS:A Rockcut Rating System for Missouri Highways.” In Proceedings of 55th Highway Geology Symposium, 406-24.

[24] Huisman, M., Hack, H., and Nieuwenhuis, J. 2004. "Observed Rock Mass Degradation and Resulting Slope Instability." Presented at Eurrock 2004, Australia.

[25] Nicholson, D. 2003. "Breakdown Mechanisms and morphoLogy for Man-Made Rockslopes in North West England.” North West Geography 3 (1): 12-26.

[26] Kuhnel, R. 2002. "Driving Forces of Rock Degradation." In Protection and Conservation of the Cultural Heritage of the Mediterranean Cities, edited by Galan, E., and Fezza, F. USA: Taylor \& Francis, 11-7.

[27] Kemeny, J., Norton, B., and Turner, K. 2006. "Rock Slope Stability Analysis Utilizing Ground-Based Lidar and Digital Image Processing." Felsbau Rock and Soil Engineering 3 (6): 8-15.

[28] Mikos, M., Vidmar, A., and Brilly, M. 2005. "Using a Laser Measurement System for Monitoring Morphological Changes on the Strug Rock Fall, Slovenia." Natural Hazards and Earth System Sciences 5: 143-53.

[29] Lim, M., Petley, D. N., Rosser, N. J., Allison, N. J., Long, A. J., and Pybus, D. 2005. "Combined Digital Photogrametry and Time-of-Flight Laser Scanning for Monitoring Cliff Evolution.” Photogrammetry Record 20:
109-29.

[30] Sagy, A., Brodsky, E. E., and Axen, G. J. 2007. "Evolution of Fault-Surface Roughness with Slip." Geology 35: 283-6.

[31] Enge, H. D., Buckley, S. J., Rotevatn, A., and Howell, J. A. 2007. "From Outcrop to Reservoir Simulation Model: Workflow and Procedures." Geosphere 3: 469-90.

[32] Otoo, J. N., Maerz, N. H., Li, X., and Duan, Y. 2013. "Verification of a 3-D Lidar Viewer for Discontinuity Orientations." Rock Mechanics and Rock Engineering Journal 46: 543-54.

[33] Donovan, J., Kemeny, J., and Handy, J. 2005. "The Application of Three-Dimensional Imaging to Rock Discontinuity Characterization, Alaska Rocks.” Presented at the 40th US Rock Mechanics Symposium, Anchorage Alaska.

[34] Feng, Q. 2001. "Novel Methods for 3d Semi-Automatic Mapping of Fracture Geometry at Exposed Rock Faces." Ph.D. thesis, KTH (Royal Institute of Technology).

[35] Feng, Q. H., and Roshoff, K. 2004. "In-situ Mapping and Documentation of Rock Faces Using a Full Coverage 3D Laser Scanning Technique." International Journal of Rock Mechanics and Mining Sciences 41 (3): 139-44.

[36] Gigli, G., and Casagli, N. 2011. "Semi-automatic Extraction of Rock Mass Structural Data from High Resolution Lidar Point Clouds.” International Journal of Rock Mechanics and Mining Sciences 48 (2): 187-98.

[37] Lato, M., Hutchinson, J., Diederichs, M., Ball, D., and Harrap, R. 2009. "Engineering Monitoring of Rockfall Hazards along Transportation Corridors: Using Mobile Terrestrial LiDAR." Natural Hazards and Earth System Sciences 9: 935-46.

[38] Otoo, J. N., Maerz, N. H., Xiaoling, L., and Duan, Y. 2011. "3-D Discontinuity Orientations Using Combined Optical Imaging and Lidar Techniques.” In Proceedings of the 45th US Rock Mechanics Symposium, 9.

[39] Slob, S., and Hack, R. 2004. "3D Terrestrial Laser Scanning as a New Field Measurement and Monitoring Technique." Engineering Geology for Infrastructure Planning in Europe 104: 179-89.

[40] Maerz, N. H., Youssef, A. M., Otoo, J. N., Kassebaum, T. J., and Duan, Y. 2003. "A Simple Method for Measuring Discontinuity Orientations from Terrestrial Lidar Images." Environmental and Engineering Geoscience 19: 185-95. 